\title{
Correction: Characterization of Anorexia Nervosa on Social Media: Textual, Visual, Relational, Behavioral, and Demographical Analysis
}

Diana Ramírez-Cifuentes ${ }^{1}$, MSc; Ana Freire ${ }^{1,2}$, PhD; Ricardo Baeza-Yates ${ }^{1,3}, \mathrm{PhD}$; Nadia Sanz Lamora ${ }^{4}$, MSc; Aida Álvarez ${ }^{4,5,6}, \mathrm{MD}, \mathrm{PhD}$; Alexandre González-Rodríguez ${ }^{4,5,6}, \mathrm{MD}, \mathrm{PhD}$; Meritxell Lozano Rochel ${ }^{7}$, BSc; Roger Llobet Vives $^{7}$, MSc; Diego Alejandro Velazquez ${ }^{8}$, MSc; Josep Maria Gonfaus $^{9}, \mathrm{PhD}$; Jordi Gonzàlez ${ }^{8}, \mathrm{PhD}$

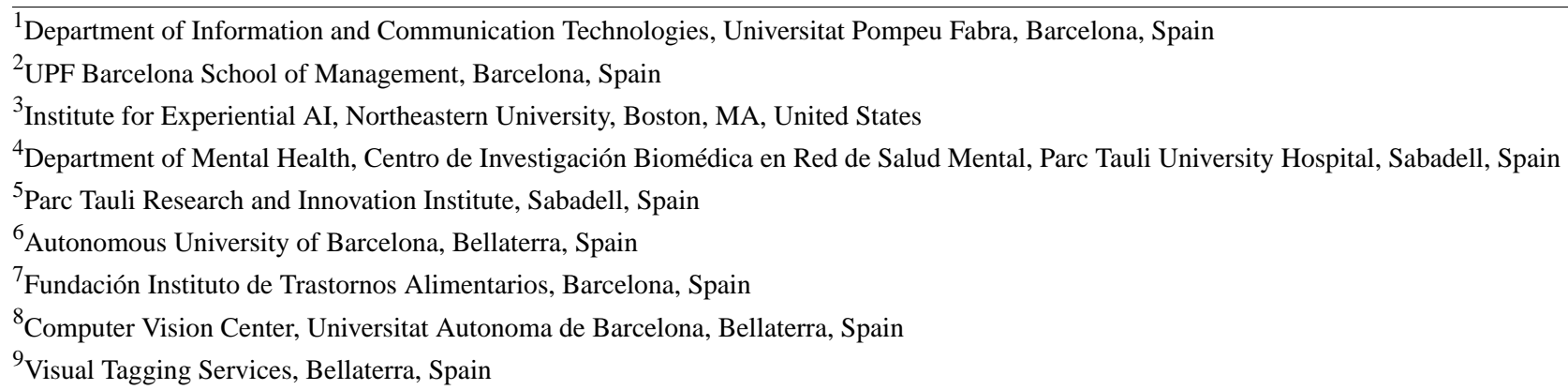

\section{Corresponding Author:}

Diana Ramírez-Cifuentes, MSc

Department of Information and Communication Technologies

Universitat Pompeu Fabra

Carrer de Tànger, 122-140

Barcelona, 08018

Spain

Phone: 34643294184

Email: diana.ramirez@upf.edu

\section{Related Article:}

Correction of: https://www.jmir.org/2021/7/e25925

(J Med Internet Res 2021;23(10):e33447) doi: 10.2196/33447

In "Characterization of Anorexia Nervosa on Social Media: Textual, Visual, Relational, Behavioral, and Demographical Analysis" (J Med Internet Res 2021; 23(7):e25925), the authors noted one error.

In the originally published paper, a reference was mistakenly placed in the following sentence in the Introduction Background section:

EDs, such as AN, are strongly related to risk factors including perfectionistic traits, parenting style [2], and the existence of comorbid mood disorders such as depression, of which 33\%-50\% of anorexia patients experience.
To address this issue and to avoid a misinterpretation of the conclusions of Reference 2, which analyses but does not state that there is a strong relation between $\mathrm{AN}$ and parenting style, the sentence has been corrected as follows:

$E D$, such as $A N$, are related to risk factors including perfectionistic traits [2], and the existence of comorbid mood disorders such as depression, of which 33\%-50\% of anorexia patients experience.

The correction will appear in the online version of the paper on the JMIR Publications website on October 12, 2021, together with the publication of this correction notice. Because this was made after submission to PubMed, PubMed Central, and other full-text repositories, the corrected article has also been resubmitted to those repositories. 
This is a non-peer-reviewed article. Submitted 08.09.21; accepted 06.10.21; published 12.10.21.

Please cite as:

Ramírez-Cifuentes D, Freire A, Baeza-Yates R, Sanz Lamora N, Álvarez A, González-Rodríguez A, Lozano Rochel M, Llobet Vives $R$, Velazquez DA, Gonfaus JM, Gonzàlez J

Correction: Characterization of Anorexia Nervosa on Social Media: Textual, Visual, Relational, Behavioral, and Demographical Analysis

J Med Internet Res 2021;23(10):e33447

URL: https://www.jmir.org/2021/10/e33447

doi: $\frac{10.2196 / 33447}{P: 34637394}$

PMID: $\underline{34637394}$

CDiana Ramírez-Cifuentes, Ana Freire, Ricardo Baeza-Yates, Nadia Sanz Lamora, Aida Álvarez, Alexandre González-Rodríguez, Meritxell Lozano Rochel, Roger Llobet Vives, Diego Alejandro Velazquez, Josep Maria Gonfaus, Jordi Gonzàlez. Originally published in the Journal of Medical Internet Research (https://www.jmir.org), 12.10.2021. This is an open-access article distributed under the terms of the Creative Commons Attribution License (https://creativecommons.org/licenses/by/4.0/), which permits unrestricted use, distribution, and reproduction in any medium, provided the original work, first published in the Journal of Medical Internet Research, is properly cited. The complete bibliographic information, a link to the original publication on https://www.jmir.org/, as well as this copyright and license information must be included. 